\title{
THERMAL INFLUENCE ON THE SURFACE INTEGRITY DURING SINGLE-LIP DEEP HOLE DRILLING OF STEEL COMPONENTS
}

\author{
J. Nickel ${ }^{1 *}$, N. Baak², P. Volke ${ }^{1}$, F. Walther ${ }^{2}$, D. Biermann ${ }^{1}$ \\ ${ }^{1}$ TU Dortmund University, Institute of Machining Technology (ISF), Dortmund, Germany \\ 2 TU Dortmund University, Department of Materials Test Engineering (WPT), Dortmund, Germany \\ ${ }^{\star}$ Corresponding author; e-mail: jan.nickel@tu-dortmund.de
}

\begin{abstract}
The thermomechanical load on the workpiece surface during the machining process strongly influences its surface integrity and the resulting fatigue strength of the components. In single-lip drilling, the measurement of the mechanical load using dynamometers is well established, but the thermal interactions between the tool and the workpiece material in the surface area are difficult to determine with conventional test setups. In this paper, the development and implementation of an in-process measurement of the thermal load on the bore subsurface is presented. The experimental setup includes a two-color ratio pyrometer in combination with thermocouples, which enable temperature measurement on the tool's cutting edge as well as in the bore subsurface. In combination, a force measurement dynamometer for measuring the occurring force and torque is used. Thus, the influence of different cutting parameter variations on the thermomechanical impact on the bore surface can be evaluated.
\end{abstract}

\section{Keywords:}

Single-lip deep hole drilling; temperature measurement; surface integrity; fatigue strength

\section{INTRODUCTION}

When using quenched and tempered high-strength steels in industrial applications, especially in the automotive industry, the fatigue behavior is of fundamental importance. In the case of machined components, the fatigue strength is influenced by the surface integrity to a large extent. $M$. Field and J. F. Kahles [Field 1964] technically defined the surface integrity as the inherent or enhanced condition of a surface produced by machining processes or other surface generation operations. Main characteristics to describe the surface integrity are the surface roughness, residual stresses, hardness and microstructure [Novovic 2004, Javidi 2008]. These factors are highly affected by the applied machining process to manufacture components and have direct influence on the fatigue strength of the components when operational dynamic loads are used in later application. Since the surface layer of a component is usually exposed to the highest loads during the machining process, it is often affected by factors like stress concentration, oxidation, microstructure transformation or burning out of alloy elements [Javidi 08]. However, some of the effects that occur during the machining process can be utilized to achieve positive effects on the surface integrity. In previous studies on the single-lip deep hole drilling process it was shown that by increasing the mechanical impact on the bore wall, a hardening of the bore subsurface in combination with a refinement of the subsurface micro structure can be achieved [Nickel 2018, Nickel 2020]. In addition, residual compressive stresses induced into the bore subsurface can counteract the tensile stresses occurring in the surface layers of the components during operational loads, thus preventing crack initiation and propagation. For components exposed to dynamic internal pressures in industrial applications, this effect is often achieved by applying additional surface treatment methods, such as a hydraulic autofrettage process [Novovic 2004, Basara 2011]. For the single-lip deep hole drilling investigated in this study, favorable process parameters (tool design, cutting conditions and sulfur content of the material) were identified in order to increase the fatigue strength by increasing the mechanical load acting on the bore subsurface, so that a subsequent surface treatment process can be obsolete for some applications [Nickel 2018, Nickel 2020]. The single-lip deep hole drilling process was identified as particularly effective for this purpose since the asymmetrical design of the tool has the effect that a large part of the cutting forces resulting from the cutting of the material are transmitted to the bore wall via the tool's guide pads. In addition to the mechanical effects used to deliberately influence the surface integrity properties, the thermal effects during single-lip deep hole drilling, which have been largely unexplored to date, also affect the surface properties produced. The development and application of an experimental setup for in-process measurements of the thermal effects on the bore wall during singlelip deep hole drilling is therefore addressed. 


\subsection{Temperature Measurement in Drilling Processes}

Temperature measurement in machining processes, especially during drilling, is particularly demanding for the measurement equipment used due to the high local temperature gradients, the fast heating rates and the poorly accessible working zones. The instationary character of the drilling process, the fast rotation of the tool as well as the complex geometry of the cutting edge have to be considered for temperature measurement setups and lead to a limitation of the choice of suitable measurement methods. Due to the characteristics of the process, the area with the major impact on the produced surface integrity is located directly at the cutting edge of the tool. Apart from high cooling lubricant pressures and hot chips, this area is subject to the greatest thermal and mechanical loads. Therefore, the positioning of the measuring technology close to the cutting zone represents an enormous challenge for the sensor technology used [Beno 2012, lovkov 2016]. In the literature, numerous studies on experimental, analytical and numerical methods with different approaches can be found so far. In most of them temperatures were detected locally in the bore subsurface, at the chip, at the tool's cutting edge, at the guide pads or the heat distribution in the workpiece was measured [Weinert 2006, Bagci 2006 , Ueda 2007, Beno 2012, Michna 2014, Girinon 2018, Islam 2019, Oezkaya 2019]. E. Oezkaya et al. used pyrometric temperature measurement to assess the thermal load along the cutting edge during the twist drilling of Inconel718. For this purpose, the optical fiber of the pyrometer was inserted into a prepared workpiece parallel to the middle axis of the bore [Oezkaya 2019]. J. Michna measured process temperatures and used a finite element chip formation model to show that the white etching layers that were produced during the twist drilling process are due to thermal stress and the associated heating and cooling rates. For the thermal analysis J. Michna used a thermographic camera and a ratio pyrometer. With four cross bores drilled into the workpiece perpendicular to the cutting edge, which served to position the optical fiber, the temperatures were detected on the cutting edge and in the workpiece [Michna 2014]. The process temperatures acting on the bore surface and subsurface during single-lip deep hole drilling have been largely unexplored to date.

\section{EXPERIMENTAL SETUP}

\subsection{Machine Tool}

The experiments were set up and carried out on an Ixion TLF 1004 deep drilling machine. The coolant lubricant supply through the inner coolant channels of the single-lip drills was kept at a constant pressure of plub $=100$ bar for all experiments. As a lubricant, the drilling oil Petrofer Isocut $\mathrm{T} 404$ with a viscosity of $\mathrm{v}=10 \mathrm{~mm}^{2} / \mathrm{s}$ was used.

\subsection{Single-Lip Deep Hole Drills}

For the drilling tests single-lip drills with a diameter of $\mathrm{d}_{\mathrm{SLD}}=5 \mathrm{~mm}$ were used, as these are common dimensions for bores in hydraulic blocks and systems. The mechanical impact on the surface integrity of different tool designs, such as varying cutting edge geometries, circumferential shapes and coatings, have been investigated in [Nickel 2018]. It was found that the design of the major cutting edge has a large impact on the occurring mechanical tool load and the resulting hardening of the bore subsurface. From these tests, a tool with a relatively large, arc-shaped outer cutting edge was selected, which results in high passive forces in the process. This causes an increase in the neutral force transmitted into the bore wall via the guide pads. Due to the circumferential shape A (according to VDI 3208) with relatively narrow guide pads, the surface pressure is increased in order to achieve a high mechanical impact on the surface and subsurface. The tool properties as well as geometry are shown in Fig. 1.

\begin{tabular}{lll}
\hline Tool diameter & $\mathrm{d}_{S L D}=5.0 \mathrm{~mm}$ \\
Tool length & $\mathrm{I}_{\mathrm{SLD}}=255 \mathrm{~mm}$ \\
Tool-head length & $\mathrm{I}_{\mathrm{SL}, \mathrm{H}}=30 \mathrm{~mm}$ \\
Outer cutting edge radius & $\mathrm{R}=2.486 \mathrm{~mm}$ \\
Inner cutting edge angle & $\mathcal{K}_{2}=105^{\circ}$ \\
Coating & & $\mathrm{TiN}$ \\
Circumferential shape & & $\mathrm{A}$ \\
\hline
\end{tabular}

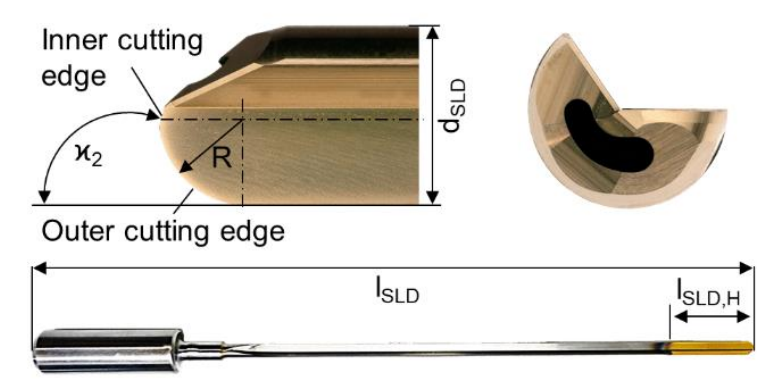

Fig. 1: Properties of the used tools.

\subsection{Material Properties and Specimen Geometry}

The material used for the tests is the quenched and tempered steel AISI 4140 (42CrMo4+QT, 1.7225). The material has a tensile strength of $\mathrm{R}_{\mathrm{m}}=960 \mathrm{MPa}$ and a hardness of $316 \mathrm{HV} 10$. The sulfur content of the material, $\mathrm{S}=0.011$ weight- $\%$ (wt- $\%$ ), is relatively low compared to conventional AISI 4140. A lower sulfur content reduces the number and size of manganese sulfide inclusions in the steel, which has a positive effect on the fatigue strength of the material. The material's chemical composition can be found in Table 1.

Table 1 : Chemical composition of the workpiece material AISI 4140 (wt-\%).

\begin{tabular}{llllllll}
\hline $\mathrm{C}$ & $\mathrm{Si}$ & $\mathrm{Mn}$ & $\mathrm{P}$ & $\mathrm{S}$ & $\mathrm{Cr}$ & $\mathrm{Mo}$ & $\mathrm{Fe}$ \\
\hline 0.41 & 0.18 & 0.85 & 0.011 & 0.011 & 1.01 & 0.18 & bal. \\
\hline
\end{tabular}

Key factor for understanding the effects of different process parameter combinations of the drilling process on the surface integrity is to analyze the associated thermomechanical load on the bore surface and subsurface. The mechanical tool load generated during the single-lip deep hole drilling process is measured at a frequency of $2 \mathrm{kHz}$ using a piezoelectric dynamometer from Kistler. The feed force $F_{f}$ and drilling torque $M_{d}$ are analyzed with the software DIAdem from National Instruments and can be correlated with the resulting mechanical impact on the bore surface. The influence of the mechanical load during the single-lip deep hole drilling process on the surface integrity was investigated in detail in [Nickel 2018, Nickel 2020].

The newly developed experimental setup to perform inprocess measurements of the temperature that affect the bore surface and subsurface is focused on in this paper. The temperature in the bores subsurface is measured thermoelectrically, whereas the tool's cutting edge and guide pad temperature is measured pyrometrically. The first step is the preparation of the round test specimens, which are chamfered from four sides using a face mill. For the installation of the temperature measurement sensors, three cross bores (B1, B2, B3) are drilled in the chamfered surface of the specimen with a distance of $\mathrm{a}_{\mathrm{CB}}=7 \mathrm{~mm}$ between these bores. This preparation of the cross bores is 
performed from three sides of the specimen, in order to be able to use one specimen for three single-lip deep hole drilling tests in position $\mathrm{X} 1, \mathrm{X} 2$ and $\mathrm{X} 3$. The cross bores for the temperature sensors are machined with a miniature drill from Guehring and have a diameter of $D_{C B}=0.4 \mathrm{~mm}$. Machining a drilling depth $\mathrm{I}_{t}$ that is as exact and reproducible as possible is crucial for a valid evaluation of the results. Depending on the function of the cross bore, the drilling depth is set to $I_{t}=5.0 \mathrm{~mm}(B 1, B 3)$, which is intended for the use of the thermocouples, and $l_{t}=5.6 \mathrm{~mm}$ (B2), for the cross bores in which the glass fiber for the pyrometer is placed. Fig. 2 shows a sketch of the test specimens prepared like this with an example of a manufactured single-lip drilling test bore at position X2.

In subsequent tests, which are not part of this paper, deep hole drilled specimens are machined into test specimens for fatigue tests. Since the critical area in which these specimens fail is located exactly in the middle of the specimens due to its design, this area was also selected for the installation of the temperature measurement sensors.
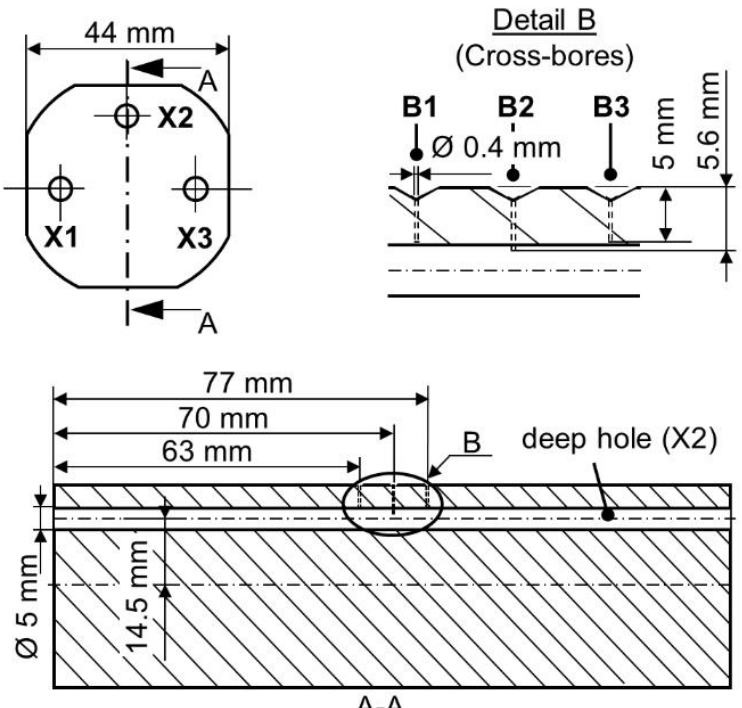

A-A

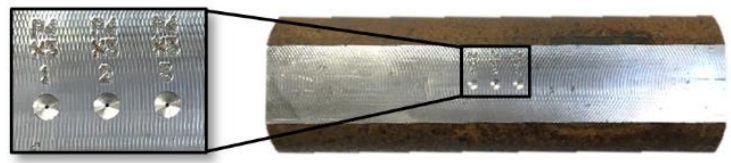

Fig. 2: Sketch of the test specimens generated and photo of the drilled cross bores.

\subsection{Temperature Measurement Equipment}

For the thermoelectric measurement two thermocouples type $\mathrm{K}$ with a diameter $\mathrm{d}_{\mathrm{TC}}=0.25 \mathrm{~mm}$ are used. These are inserted into the cross bores B1 and B3 using a graphitecontaining thermal-conductive paste with a thermal conductivity of $\lambda=10.5 \mathrm{~W} / \mathrm{mK}$ and are then fixed with an adhesive. In addition to the small radial air cavity of $\Delta 75 \mu \mathrm{m}$ between the thermocouple and the bore wall, the use of a thermal conductive paste led to a reduction of the recorded measurement deviation tolerance, since the heat transfer between the thermocouple and the material is ensured. The pyrometric temperature measurement was performed with a fiber optic ratio pyrometer type FIRE-3 from the manufacturer en2Aix. The optical fiber with a diameter of $\mathrm{d}_{\mathrm{F}}=0.33 \mathrm{~mm}$ is glued into the cross bore B2, so that it protrudes about $L_{F}=600 \mu \mathrm{m}$ into the single-lip bore created in the subsequent test. This test set-up ensures that the fiber is cut several times by the cutting edge of the single- lip drill during the machining process. The thermal radiation emitted by the cutting of the workpiece material is absorbed by the fiber and converted into a temperature by the pyrometer software. An overview of the test setup including the equipment for the temperature and tool load measurement is given in Fig. 3. The cutting parameters for the single-lip deep hole drilling process for this test series to measure the thermo-mechanical load are kept constant at $\mathrm{v}_{\mathrm{c}}=65 \mathrm{~m} / \mathrm{min}$, $f=0.1 \mathrm{~mm}$. For the visualization of the microstructure in the bore subsurface, a Zeiss Axio Imager M1m light microscope was used.

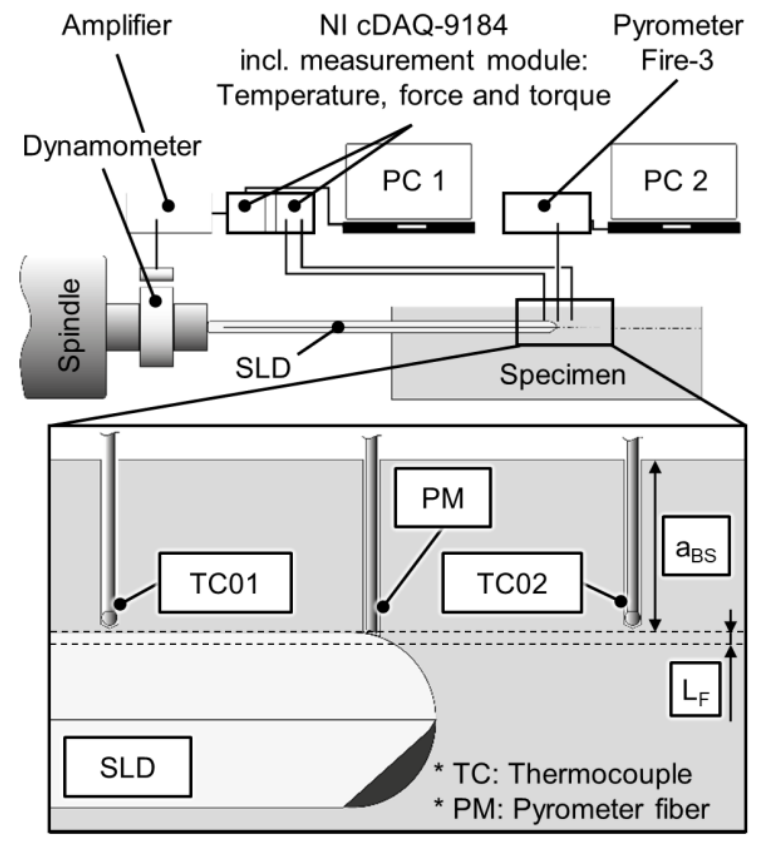

Fig. 3: Sketch of the experimental setup including temperature and force measurement sensors.

\subsection{Eddy-Current Measurements}

The non-destructive assessment of the surface integrity was performed by means of eddy-current measurements with an Elotest PL-600 and a custom designed sensor with a diameter of $4 \mathrm{~mm}$ from Rohmann. The measurements were carried out with an eddy-current frequency of $900 \mathrm{kHz}$ with a preamplification of $30.50 \mathrm{~dB}$, an amplification of $30.00 \mathrm{~dB}$ and an $x$ - and $y$-spread of $6 \mathrm{~dB}$. The third harmonic was considered.

\section{RESULTS AND DISCUSSION}

Of particular importance for the produced surface integrity are the maximum thermomechanical loads occurring during the drilling process. Such loads can cause phase transformations in the subsurface microstructure, especially if a critical threshold is exceeded. Highly critical for the fatigue strength of components is the formation of thermally induced brittle martensitic layers in the subsurface microstructure, so-called white etching layers (WEL), which are often accompanied by the formation of undesirable tensile residual stresses. The risk of WEL formation exists especially when the austenitizing temperature is reached or exceeded. As a result, the subsurface microstructure can be austenitized for a brief moment and then transformed into a martensitic microstructure by subsequent quenching with the cooling lubricant [Koster 1970, Griffiths 2001, Pan 2017]. For this reason, the maximum temperatures $\mathrm{T}_{\max }$ are the main focus of the analyses when evaluating the temperature measurements. However, the critical threshold for structural microstructure changes is influenced by a 
superposition of thermal and mechanical effects on the bore's surface and subsurface, so that the thermomechanical load in conjunction has to be regarded.

\subsection{Thermoelectric Measurement}

Fig. 4 exemplary shows a temperature curve as a function of the process time th measured during the single-lip deep hole drilling process using two thermocouples TC01 and TC02. For each thermocouple measurement, the maximum temperature $\mathrm{TTC}_{\mathrm{T}, \max }$ is evaluated. The temperature peaks are about 2 seconds apart, which is due to the distance of the measuring positions along the single-lip bore of STC01$\mathrm{TC} 02=14 \mathrm{~mm}$.

\begin{tabular}{|ll|}
\hline Material: & 42CrMo4+QT, (S =0.011 wt-\%) \\
Tool: & SLD, $\varnothing 5 \mathrm{~mm}$ \\
Coolant: & Oil, $\mathrm{p}_{\text {coolant }}=100 \mathrm{bar}$ \\
Cutting Speed: & $\mathrm{v}_{\mathrm{c}}=65 \mathrm{~m} / \mathrm{min}$ \\
Feed: & $\mathrm{f}=0.1 \mathrm{~mm}$ \\
Thermocouple: & Typ K $/ \varnothing 0.25$ \\
\hline
\end{tabular}

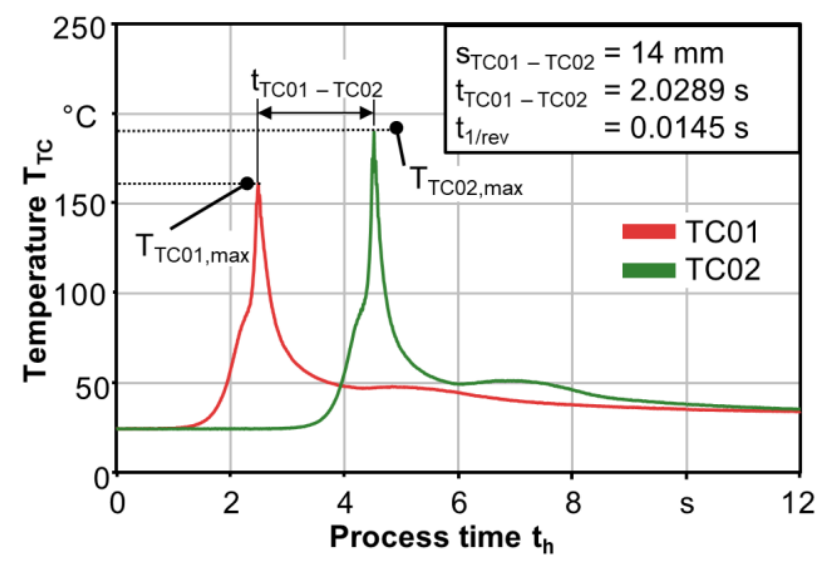

Fig. 4: Exemplary temperature profile of the thermocouples TCO1 and TC02 including definition of the maximum temperature $T_{T C, \max }$ from the thermoelectric measurement.

The nominal distance of the thermocouples to the bore wall of the single-lip bore is set by the depth of the cross bores $D_{C B}=0.4 \mathrm{~mm}$. Due to the position of the temperature measuring sensors in the center of the sample and thus at a drilling depth of about I $=70 \mathrm{~mm}$ of the single-lip deep hole drilling process, the actual distance of the thermocouples is additionally influenced by the straightness deviation of the single-lip drill. In order to consider this factor for the temperature measurements, cross sections of the areas where the single-lip drill passed the cross bores with the thermocouples are prepared and analyzed. This enables a precise determination of the distance of the thermocouples' position in relation to the bore wall of the $D_{S L B}=5 \mathrm{~mm}$ single-lip bore. This measurement is carried out on the center line of the cross bore. Due to the diameter of the thermocouple of $\mathrm{d}_{\mathrm{TC}}=0.25 \mathrm{~mm}$, which was installed in the center of the bore with thermally conductive paste, this enables a comparable measurement for all micrographs of the cross sections. During preparation of the cross sections, the diameter of the cross bores was measured and checked to ensure that the correct plane of the section is achieved. The measured distances are set in proportion to the measured temperatures for thermocouple 1 (TC01) and thermocouple 2 (TC02).

When analyzing the micrographs, three cases are distinguished, which occur during the in-process temperature measurement with thermocouples, due to the straightness deviation: 1.) The single-lip drilled bore runs at a measurable distance aвs to the cross bore containing the thermocouple. 2.) The nominal distance of the single-lip bore to the cross bore is completely compensated by the straightness deviation, so that the cross bore is briefly met by the cutting edge of the single-lip drill. However, due to the deformation of the workpiece material at the cutting edge of the tool, the cross bore is kept closed. In this case, the distance between the thermocouple and the single-lip bore is not existent (aBs $=0 \mu \mathrm{m})$. 3.) The cross bore is hit and opened by the single-lip drill so that cooling lubricant can enter the cross bore. In this case, there is no distance aBs between the single-lip bore and the thermocouple too, but the results are additionally distorted by the contact of the cooling lubricant with the thermocouple and cannot be used afterwards.

A series of 37 micrographs of cross sections were prepared and analyzed after the drilling tests to measure the actual distance of the thermocouple to the bore wall. For further evaluation, only those measurements were selected in which a distance to the single-lip bore was ensured during the drilling process and the measurement was not influenced by the contact of the single-lip drilled bore with the cross-bore. An exemplary representation of the determination of these actual distances aBs using the micrographs of some cross bores is shown in Fig. 5 (bottom). The measured maximum temperatures $\mathrm{T}_{\mathrm{TC} \text {,max }}$ are plotted over the respective distance to the bore wall in Fig. 5 (top).

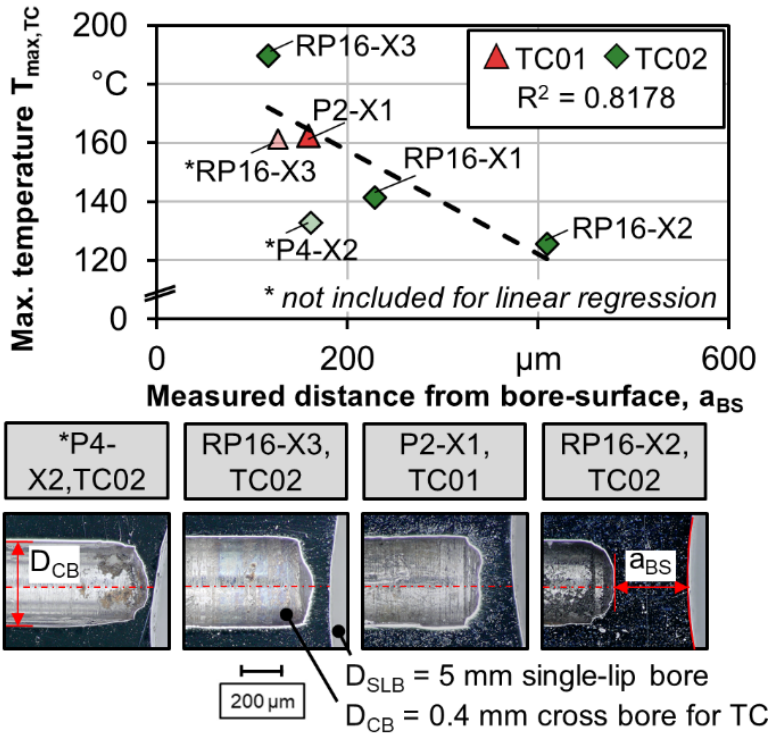

Fig. 5: Maximum temperatures $T_{T C, \max }$ of TC01 and TC02 for different measured distances from the bore surface $a_{B S}$

(top); Micrographs of the cross bores (bottom).

The maximum temperature detected by the thermocouples is $\mathrm{T}_{\mathrm{TC} 02, \max }=189.8^{\circ} \mathrm{C}$ at a distance of $\mathrm{aBS}_{\mathrm{BS}}=117 \mu \mathrm{m}$ from the bore surface. With an increasing distance from the bore subsurface lower maximum temperatures are measured, with the lowest temperature of $\mathrm{T}_{\mathrm{TC} 02, \max }=102.5^{\circ} \mathrm{C}$ at a distance of $\mathrm{aBS}_{\mathrm{BS}}=265 \mu \mathrm{m}$ from the bore wall.

Even though a relatively high coefficient of determination of $\mathrm{R}^{2}=0.8178$ can be achieved for the regressive curve shown in Fig. 5, outliers such as the P4-X2 measurement and the relatively high number of eight non-evaluable measurements show that thermoelectric temperature measurement has only limited suitability for in-process measurements during the single-lip deep hole drilling process. Therefore, pyrometric temperature measurement is applied as an alternative method to access the thermal influence on the surface integrity. 


\subsection{Pyrometric Temperature Measurement}

The thermal radiation emitted in the working zone during the single-lip deep hole drilling process is transformed into two voltage signals using a ratio pyrometer and then converted into a temperature. Due to the used test setup, the temperatures measured correspond to those directly at the cutting edge and flank face (sector 1) or the guide pads (sector 2) of the drilling tool. These temperatures have a direct effect on the bore surface, which is in contact with the tool. The output signals of the pyrometer are two voltage signals (voltage channel 1 to 2) gained from the two different wavelengths detected by the pyrometer. The level of the voltage and corresponding temperatures while the single-lip drill passes the measuring position are shown in Fig. 6. The periodic signal pattern of the voltage channels results from the passing of the tool's cutting edge along the embedded optical fiber with each rotation of the tool. Thus, at each contact with the cutting edge, the emitted thermal radiation is detected by the fiber and output as a voltage signal.

\begin{tabular}{ll}
\hline Material: & 42CrMo4+QT, (S =0.011 wt-\%) \\
Tool: & SLD, $\varnothing 5 \mathrm{~mm}$ \\
Coolant: & Oil, $\mathrm{p}_{\text {coolant }}=100 \mathrm{bar}$ \\
Cutting Speed: & $\mathrm{v}_{\mathrm{c}}=65 \mathrm{~m} / \mathrm{min}$ \\
Feed: & $\mathrm{f}=0.1 \mathrm{~mm}$ \\
Gain Factor: & $\mathrm{G} 1: 1 * 10^{8} / \mathrm{G} 2: 1 * 10^{8}$ \\
\hline
\end{tabular}

Voltage Channel $1 \quad$ Voltage Channel 2 Temperature

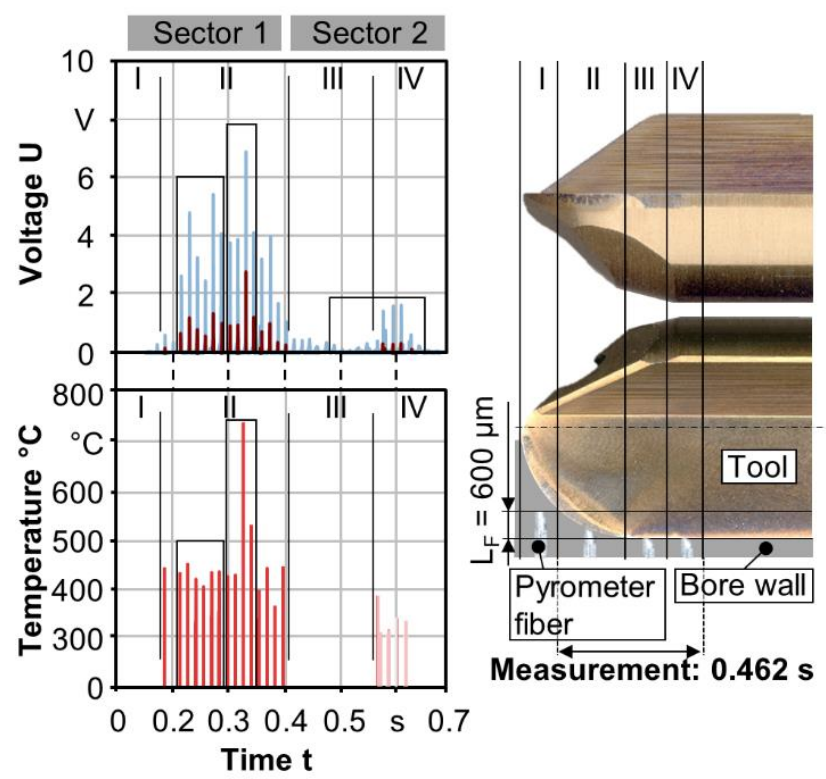

Fig. 6: Exemplary voltage and temperature measurement at different tool cutting edge positions.

Fig. 6 visualizes the contact situation between the optical pyrometer fiber and the drilling tool for different phases of the measurement in the time progression. Phase I represents the first contact of the radius-shaped cutting edge with the fiber. In phase II the position and the angle of the pyrometer's measuring spot on the cutting edge changes with every revolution of the tool due to the progressive movement of the drill in the feed direction. In the area where the fiber meets the flank face of the cutting edge almost orthogonally the highest voltage signals and correlating temperatures are measured. In phase III the measuring spot of the pyrometer hits the transition of the tool's cutting edge to the guide pads, where the measured voltages drop considerably. In the following phase IV, the heat radiation of the guide pads is detected, which in turn leads to a second increase in the measured voltages and temperatures.

These four phases of contact between tool and pyrometry fiber can be divided into two sectors: In Sector 1, the optical fiber is cut several times by the cutting edge of the tool until the relative position of the tool to the optical fiber at the transition to the guide pads of the tool is reached. In this sector, the cutting of the material mainly produces the measured thermal radiation. In the further course of the process, which is the second sector, the guide pads pass the optical fiber with each rotation of the drill. The thermal radiation emitted by the guide pads thus allows to detect the thermal energy generated mainly by the friction between guide pads and bore surface. Both, the heat generated by cutting the material and the heat generated by friction affect the integrity of the bore surface. As with thermoelectric temperature measurement, analyzing the maximum temperature $T_{\max }$ during the measurement is focused, as a change in microstructure can be assumed if the austenitization temperature of the material is exceeded.

The maximum temperatures measured with the pyrometer during the drilling process are shown in Fig. 7. In the diagram, these values are visualized as box plots and shown next to the thermoelectric measurement values in the bore subsurface, allowing a comparison of the two temperature measurement approaches. In addition to the mean values of the measured maximum temperatures with regard to all of the tests carried out, the spread of the measured values becomes apparent as so-called whiskers of the box-plots. The temperatures measured pyrometrically directly at the tool are on average significantly higher $\left(T=583^{\circ} \mathrm{C}\right)$ than the temperatures measured thermoelectrically at a certain distance to the bore wall in the subsurface $\left(T=122^{\circ} \mathrm{C}\right)$. In addition, the spread of the values in pyrometric temperature measurement is significantly larger.

\begin{tabular}{ll}
\hline Material: & 42CrMo4+QT, (S = 0.011 wt-\%) \\
Tool: & SLD, $\varnothing 5 \mathrm{~mm}$ \\
Coolant: & Oil, $\mathrm{p}_{\text {coolant }}=100 \mathrm{bar}$ \\
Cutting Speed: & $\mathrm{v}_{\mathrm{c}}=65 \mathrm{~m} / \mathrm{min}$ \\
Feed: & $\mathrm{f}=0.1 \mathrm{~mm}$ \\
\hline
\end{tabular}

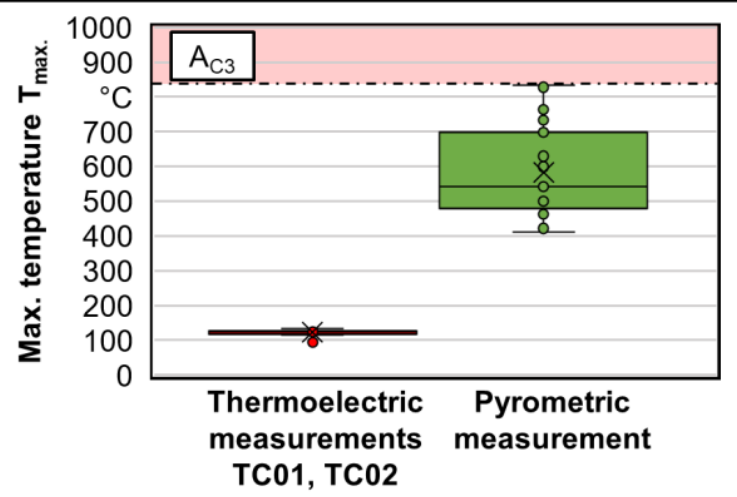

Fig. 7: Comparison of measured temperatures for thermoelectric and pyrometric measurements.

The differences in the level of the measured temperatures can be explained by the measuring position and the response time of the used sensors. For the thermoelectric measurement, the process-generated heat must first distribute in the workpiece material between the tool and the measuring position as well as in the thermocouple itself. Therefore, it is less sensitive to short temperature peaks, than the pyrometric measurement. Pyrometry allows to detect even short temperature peaks directly at the tool's 
cutting edge as well as on the tool's guide pads. This contact area between the tool and the bore wall is particularly critical for temperature induced short-term austenitization and formation of WEL. With the here used combination of cutting parameters almost all measured maximum temperatures during the single-lip deep hole drilling processes are below the austenitization temperature of AISI 4140 , which is about at $A_{c 3} \approx 840^{\circ} \mathrm{C}$. However, the highest temperature measured during the tests showed a value of $\mathrm{T}=833^{\circ} \mathrm{C}$, which is close to the critical temperature. In combination with the process-related mechanica impact on the bore wall, such temperature peaks can cause a localized transformation of the subsurface microstructure. The material at the bore subsurface can be austenitized to a depth of a few micrometers in the bore wall by the thermomechanical effects occurring on the tool's cutting edge. As the tool continues its rotation, the deep drilling oil with a much lower temperature is subsequently flowing around this area and quenching it. These temperature differences become visible in the individual voltage peaks of the temperature measurement, which in sector 1 (Fig. 6) represent one revolution of the tool. Although the maximum temperature measured in this sector does not have a permanent effect on the bore wall, but can apparently occur infrequently, a white etching layer can be produced by occurring temperature peaks during the drilling process. Such effects can cause an embrittlement of the bore surface, in which also tensile residual stresses can result due to the directly successive strong heating and quenching. The so affected parts of the bore wall can be a critical spot for component failure in the later application of a component. Therefore, by understanding the occurring effects and adjusting the process parameters, an attempt can be made to reduce the thermal load acting on the bore wall during the single-lip deep hole drilling. Thus, the temperature is aimed to constantly stay below the critical level for thermally induced restructuring of the material microstructure.

\subsection{Mechanical Tool Load and Subsurface Micro- structure}

The mechanical tool load generated during the single-lip deep hole drilling process is measured continuously. Since the level of the mechanical tool load during the process stays on a constant level, it is evaluated as the mean value for one entire bore. In addition, the standard deviation of all measured data points for a bore is evaluated, which is a measure for vibrations occurring during the process. The results for the mechanical tool load measurement are presented in Fig. 8. An average feed force of $F_{f}=428 \mathrm{~N}$ and an average drilling torque of $M_{d}=1.68 \mathrm{Nm}$ is measured during the process. The mechanical impact of the single-lip deep hole drilling on the bore edge zone has already been focus of the analysis in previous investigations [Nickel 2018, Nickel 2020]. The effects of the combination of thermal and mechanical influence on the bore subsurface is visualized in form of micrographs of cross sections of the bore wall in Fig. 8. In this image, the plastic deformation of the material's microstructure caused by the drilling torque acting in the cutting direction and the associated microstructure refinement can be observed. The mechanical hardening of the bore subsurface and the introduction of residual compressive stresses in this area are desired effects to positively influence the surface integrity properties to achieve a higher fatigue strength under subsequent dynamic load. The cross section shows a mechanical microstructure refinement up to a penetration depth of about $40 \mu \mathrm{m}$. In the areas directly adjacent to the bore wall, a lighter coloring of the etched microstructure can be seen, which indicates the formation of a white etching layer. However, this does not occur along the entire section of the bore wall shown in this image, but only in a partial area of it. In his investigations on a twist drilling process, J. Michna has already established that the cause of the formation of white etching layers lies in the superposition of the thermal and mechanical effects onto the surface [Michna 2014].

\begin{tabular}{|ll|}
\hline Material: & 42CrMo4+QT, (S = 0.011 wt-\%) \\
Tool: & SLD, $\varnothing 5 \mathrm{~mm}$ \\
Coolant: & Oil, $\mathrm{p}_{\text {coolant }}=100 \mathrm{bar}$ \\
Cutting Speed: & $\mathrm{v}_{\mathrm{c}}=65 \mathrm{~m} / \mathrm{min}$ \\
Feed: & $\mathrm{f}=0.1 \mathrm{~mm}$ \\
\hline
\end{tabular}

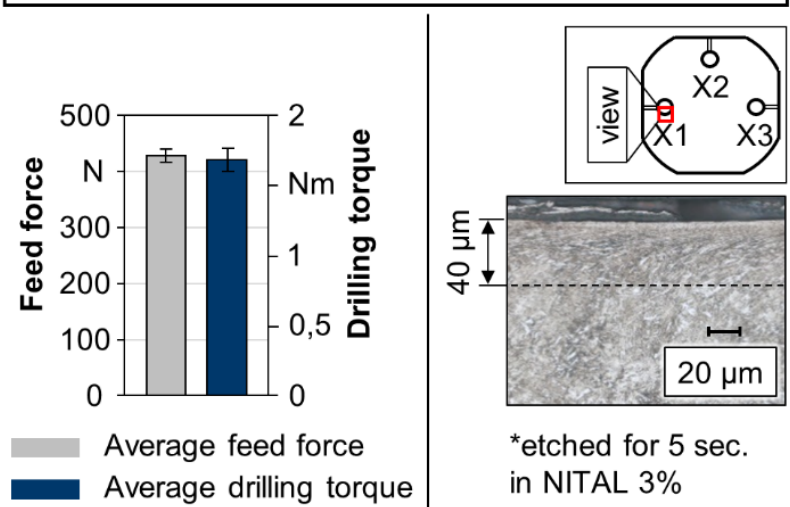

\section{Fig. 8 : Mechanical tool load (left) and subsurface micro- structure (right).}

The results of the deep drilling tests carried out here also indicate that the thermomechanical effects of the drilling process on the bore wall shown in Fig. 8 induced a localized transformation of the bore subsurface microstructure. The measured temperature peaks in combination with the measured cutting forces are thus at the limit of or in a critical parameter range, where negative consequences for the surface integrity and the associated fatigue strength of the samples can be assumed. In addition to the level of mechanical tool load, the values of the temperature measurement carried out by means of a ratio pyrometer can be used as an indicator that a critical temperature for deterioration of the bore subsurface properties has been reached. By using these analyzing methods in future investigations under variation of the cutting conditions and cooling lubrication strategy, the impact of these process parameters on the generated thermal load during the single-lip deep hole drilling process and the associated effects on the surface integrity are going to be investigated.

In a series of tests already carried out, in which the cutting speed was varied in three steps of $v_{c}=50,65$ and $80 \mathrm{~m} / \mathrm{min}$, the surface integrity properties were assessed by eddy current measurements. These results are presented in the following section.

\subsection{Eddy-current assessment of the surface integrity}

The assessment of the resulting surface integrity was performed by means of eddy-current measurements. Fig. 9 shows exemplary results of bores drilled with varying cutting speed. Eddy-current measurements are sensitive to changes in microstructure, hardness, etc. It can clearly be seen that the different resulting surface conditions can be separated by these measurements. Previous investigations have lead to the assumption that the correlation is based on changes in the subsurface microstructure [Nickel 2018]. The thermal penetration of the bore wall prevailing for these cutting speed variations in addition to different feed rates will be investigated in future test series in order to analyze the impact of different parameter combinations on the 
surface integrity. The results are to be put in context with the results of the in-process measurements and the destructive analysis methods of the surface integrity properties. The aim is to identify a range for values of the non-destructive eddy-current measurement at which the desired surface integrity properties are obtained.

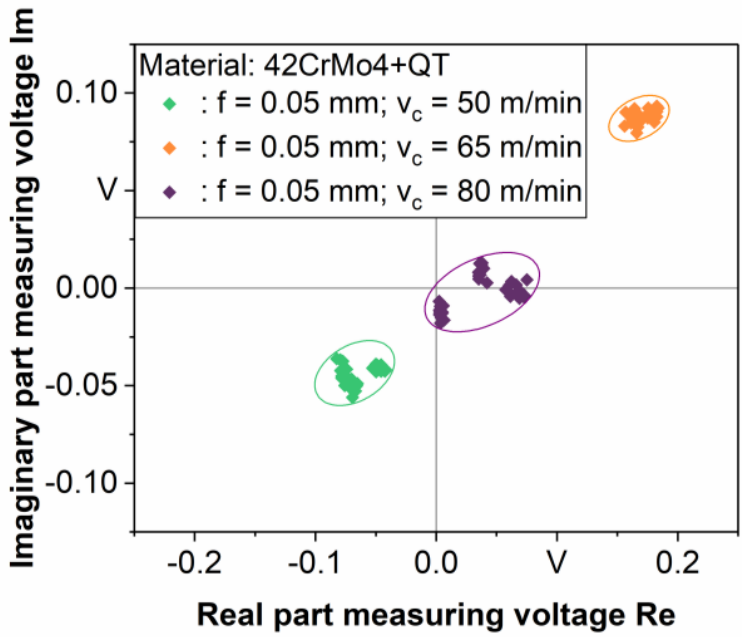

Fig. 9 : Exemplary eddy-current measurement at bores drilled with different cutting parameters.

\section{SUMMARY AND OUTLOOK}

The objective of this paper was to implement a combination of measurement methods to assess the thermomechanical impact of the single-lip deep hole drilling process on the bore wall. In particular the measurement of the thermal loads occurring during the process were in focus and were realized by means of two different approaches. A thermoelectric temperature measurement setup was applied in the bore subsurface at a defined nominal distance of $a_{B S}=50 \mu \mathrm{m}$ from the bore wall. The temperature measurement by means of ratio pyrometers measured the heat radiation emitted directly at the tool's cutting edge and the guide pads. By analyzing the subsurface microstructure using micrographs of cross sections of the bore wall, the effects of the drilling process could be correlated with the determined thermomechanical effects acting on the bore wall. In addition, the eddy-current assessment was applied as a non-destructive method to characterize the produced surface integrity under varying cutting conditions. The findings obtained can be summarized as follows:

- The temperature measurement using thermocouples offers a comparatively inexpensive possibility to determine temperatures in the bore subsurface zone. Deviations in the distance between the thermocouple position and the bore subsurface, however, can be caused by the straightness deviation of the tool and be an undesirable influencing factor. The height of the temperature directly at the bore surface, which usually leads to the formation of white etching layers of only a few micrometers thickness, cannot be assessed directly using a thermoelectric measurement setup.

- The temperature measurement by means of ratio pyrometry allows the in-process temperature measurement directly at the tool's cutting edge and at the guide pads of the tool with a frequency of $7 \mathrm{kHz}$. The temperatures determined with this setup represent the thermal load acting directly on the produced bore surface. The high sampling rate of the pyrometer allows to analyze the maximum temperature at each revolution of the tool when passing the optical fiber at the corresponding measuring position.

- The average of all maximum temperatures $T_{\max }$ measured in the tests by the pyrometric measurement are below the austenitizing temperature of the material AISI 4140, but some of the values approach the range of this critical temperature.

- The feed force and torque occurring in the drilling process was measured and evaluated in the form of the mechanical tool load. The resulting effects on the bore's subsurface integrity were documented in form of a microstructure refinement up to depth of approximately $40 \mu \mathrm{m}$ in the subsurface zone of the bore.

- Further, the analysis of the bore wall cross-sections shows a partial microstructural transformation in the subsurface microstructure in the form of a white etching layer (WEL), which, at the set process parameters, is caused by the superposition of thermal and mechanical effects acting on the bore wall.

In further investigations, the test setup using pyrometric temperature measurement during the single-lip deep hole drilling process, which has been successfully applied in this study, is to be applied for further cutting value combinations and cooling lubricant variants. Thereby, a holistic consideration of the thermomechanical effects on the bore wall and the associated surface integrity are to be enabled. In the future, this data will be used to model the interactions between the process parameters during the single-lip deep hole drilling and the produced surface integrity properties that are decisive for the fatigue strength of the machined specimens.

\section{ACKNOWLEDGMENTS}

The project "Investigations on the influence of machining and Sulphur content on the fatigue strength of the quenched and tempered steel 42CrMo4+QT" was funded by the Deutsche Forschungsgemeinschaft (DFG, German Research Foundation) - project number 320296624.

\section{REFERENCES}

[Bagci 2006] Bagci, E.; Ozcelik, B.: Finite element and experimental investigation of temperature changes on a twist drill in sequential dry drilling. The International Journal of Advanced Manufacturing Technology, 2006, Vol. 28, 680-687. doi: 10.1007/s00170-004-2417-8

[Basara 2011] Basara, A.; Nicolas, A.; Schluecker, E.: Influence of the pressure holding time on strain generation in fuel injection lines. International Journal of Pressure Vessels and Piping. 2011, Vol. 88, 132-137. doi: 10.1016/j.jpvp.2011.02.003

[Beno 2012] Beno, T.; Hulling, U.: Measurement of cutting edge temperature in drilling. Procedia CIRP, Vol. 3, 2012, 531-536. doi: 10.1016/j.procir.2012.07.091

[Field 1964] Field, M.; Kahles, J. F.: The surface integrity of machined and ground high strength steels. DMCl Report 1964, No. 210, 54-77

[Girinon 2018] Girinon, M.; Dumont, F.; Valiorgue, F.; Rech, J.; Feulvarch, E.; Karaouni, H.; Jourden, E.: Influence of lubrication modes on residual stresses generation in drilling of $316 \mathrm{~L}, 15-5 \mathrm{PH}$ and Inconel 718 alloys. Procedia CIRP, 2018, Vol. 71, 41-46. doi: 10.1016/j.procir.2018.05.020

[Griffiths 2001] Griffiths, B.: Surface Integrity \& Functional Performance. Manufacturing Surface Technology, 2001. doi: 10.1016/B978-1-85718-029-9.X5000-8 
[lovkov 2016] lovkov, Ivan: Technologische Analyse des Tiefbohrens mit Minimalmengenschmierung und simulationsbasierte Kompensation des Mittenverlaufs. Dissertation, Vulkan Verlag, 2016. doi: 10.17877/DE290R-17418

[Islam 2019] Islam, M.N.; Boswell, B.: Effect of cooling methods on cutting temperature, cutting force and hole quality in drilling of three ferrous alloys. Journal of Physics: Conference Series, 2019, Vol. 1150, doi: 10.1088/1742$6596 / 1150 / 1 / 012068$

[Javidi 2008] Javidi, A.; Rieger, U.; Eichlseder, W.: The effect of machining on the surface integrity and fatigue life. International Journal of Fatigue, 2008, Vol. 30, No. 10-11, 2050-2055. doi: 10.1016/j.jfatigue.2008.01.005

[Koster 1970] Koster, W. P.; Field, M.; Louis, J. F.; Luciano, R. G.; Kahles, J. F. : Surface integrity of machined structural components. Technical Report AFML-TR-70-11, 1970, MMP Project No. 721-8, Metcut Research Associates Inc.

[Michna 2014] Michna, J.: Numerische und experimentelle Untersuchung zerspanungsbedingter Gefuegeumwandlungen und Modellierung des thermo-mechanischen Lastkollektivs beim Bohren von 42CrMo4. Dissertation. KIT, Karlsruhe, 2014. doi: 10.5445/IR/1000038782

[Nickel 2018] Nickel, J.; Baak, N.; Biermann, D.; Walther, F.: Influence of the deep hole drilling process and sulphur content on the fatigue strength of AISI 4140 steel components. Procedia CIRP, 2018, Vol. 71, 209-214. doi: 10.1016/j.procir.2018.05.069

[Nickel 2020] Nickel, J., Baak, N., Walther, F., Biermann, D.: Influence of the feed rate in the single-lip deep hole drilling process on the surface integrity of steel components. Advanced Surface Enhancement - Proc. of 1st Int. Conference on Advanced Surface Enhancement (INCASE 2019), 2020, 198-212. ISBN 978-981-15-0054-1

[Novovic 2004] Novovic, D.; Dewes, R. C.; Aspinwall, D. K.; Voice, W.; Bowen, P.: The effect of machined topography and integrity on fatigue life. International Journal of Machine Tools \& Manufacture, 2004, Vol. 44, No. 2-3, 125-134. doi: 10.1016/j.ijmachtools.2003.10.018

[Oezkaya 2019] Oezkaya, E.; Buecker, M.; Strodick, S.; Biermann, D.: A thermomechanical analysis leading to a novel flank face design providing longer tool lives for tools used in the drilling of Inconel 718. The International Journal of Advanced Manufacturing Technology, 2019, Vol. 102, 2977-2992. doi: 10.1007/s00170-019-03417-7

[Pan 2017] Pan, R. ; Ren, R., Chen, C. ;Zhao, X. : The microstructure analysis of white etching layer on treads of rails. Engineering Faliure Analysis, 2017, Vol. 82, 33-46. doi : 10.1016/j.engfailanal.2017.06.018

[Ueda 2007] Ueda, T.; Nozaki, R.; Hosokawa, A.: Temperature measurement of cutting edge in drilling - effect of oil mist. CIRP Annals, 2007, Vol. 56, No. 1, 93-96. doi: 10.1016/j.cirp.2007.05.024

[Weinert 2006] Weinert, K.; Gruenert, S.: Waermeentwicklung beim Bohren - Auswirkungen bei Variation von Bearbeitungsparametern, Werkstoffen und Werkzeugdurchmessern. ZWF Zeitschrift f. Wirtschaftlichen Fabrikbetrieb, 2006, Vol. 101, No. 9, 300-504. doi: 10.3139/104.101055 